\title{
Land Use/Land Cover Changes from 1995 to 2017 in Trang Bang, Southern Vietnam
}

\author{
Thi Bich Phuong Nguyen1, Xin Zhang1, Wei Wu², Hongbin Liu ${ }^{3 *}$ \\ ${ }^{1}$ College of Resources and Environment, Southwest University, Chongqing, China \\ ${ }^{2}$ College of Computer and Information Science, Southwest University, Chongqing, China \\ ${ }^{3}$ College of Resources and Environment, Southwest University, Chongqing, China \\ Email: *lhbin@swu.edu.cn
}

How to cite this paper: Nguyen, T.B.P., Zhang, X., Wu, W. and Liu, H.B. (2019) Land Use/Land Cover Changes from 1995 to 2017 in Trang Bang, Southern Vietnam. Agricultural Sciences, 10, 413-422. https://doi.org/10.4236/as.2019.103033

Received: March 1, 2019

Accepted: March 26, 2019

Published: March 29, 2019

\begin{abstract}
Trang Bang is the largest agricultural production district of TayNinh province, Vietnam that has a great influence on the socio-economic development of the whole province. This study assessed land use - land cover change in Trang Bang district from 1995 to 2017, the results provide scientific evidence for the safe and effective identification of causes and safeguards for mulch. The study was conducted by an expert classification system and the land use/land cover (LULC) was classified into 6 classes: food-crops, fruit-tree, water, built-up, industry and shrub. The result showed that the LULC there decreased between 1995 and 2017. All the two land cover types (food-crops, fruit-tree) decreased $141.2 \mathrm{~km}^{2}$ (41.4\%) in 2017 compared with 1995, while the area of industrial and urban land (industry, built-up) increased $70.0 \mathrm{~km}^{2}$ (20.6\%). The overall classification accuracies in 1995, 2007, and 2017 were $94.2 \%, 98.0 \%$, and $96.3 \%$ respectively. The overall kappa coefficients for the image classification were 0.90, 0.97, and 0.94 in 1995, 2007, and 2017 respectively. In general, the average classification was above $90 \%$, and this proved that the classification was reliable and acceptable. The result show that the LULC in the study area decreased during 1997-2017 and tended to decrease in recent years.
\end{abstract}

\section{Keywords}

Sai Gon River, Dau Tieng Dam, Land Use/Land Cover, Trang Bang, Classification, Remote Sensing

\section{Introduction}

Land use/land cover (LULC) change refers to the change of mantle that includes changes in the type of mantle (LULC change conversion) and changes within the 
mantle itself (LULC change modification). Information about LULC and change of the LULC are essential for proper planning, management and utilization of natural resources, environmental protection. Assessment of the LULC change helps to understand better the relationships between humans and the environment to manage and exploit resources optimally for sustainability. There are many methods and tools for performing classification and evaluation of mantle variation. In particular, the use of multi-temporal remote sensing data provides continuous and accurate information on the status of the mantle. The issue of remote sensing data and GIS application for updating the status and mapping of land cover to better manage natural resources that has been made by scientists from all over the world [1]-[6]. Most of them focused on developing countries (e.g. Thai Land [1], China [2], [3], Africa [4], [5], Indonesia [6]). However, few works were conducted in Vietnam, which is also a developing country with a long history of agriculture and a large population depending on land and its resources for their daily activities.

Trang Bang is a typical agricultural region of southern Vietnam. It is close to Ho Chi Minh City which is the economical center of Vietnam. In recent years, this area has observed rapid urbanization, and many industrial parks have sprung up causing a dramatic decline in agricultural land area, which prolongs dry season and lack of water, threatening agricultural production and people's lives. Because this locality has concentrated on economic development in the direction of industrialization, the area of agricultural land has been reduced dramatically since 1995. Most cultivated land has been changed to built-up and industrial land, which make the land cover change seriously. The dense population and industrial zones have increased rapidly, but there is no scientific basis to conclude that the coating in this area is declining. Therefore, the objective of the current study is to explore the changes of LUCC during the last two decades (1995-2017) using Landsat satellite imageries in Trang Bang, southern Vietnam and identify the main factors driving the changes. The findings are expected to provide valuable information for local government to design appropriate policies for optimal use of land.

\section{Data and Methods}

\subsection{Study Area}

Trang Bang $\left(10^{\circ} 56^{\prime} \mathrm{N}\right.$ to $11^{\circ} 15^{\prime} \mathrm{N}$ and $106^{\circ} 10^{\prime} \mathrm{E}$ to $\left.106^{\circ} 28^{\prime} \mathrm{E}\right)$ is located in southern Vietnam and is the most populous district of TayNinh province (Figure 1). The study area has a natural area of $340.7 \mathrm{~km}^{2}$ and population is 160,824 persons (2017) [7].Water resources in Trang Bang are diversified, including two main river systems: Sai Gon and Vam Co Dong rivers and Dau Tieng dam. This is one of the largest dam and has had an impact on Vietnam's agricultural production. This place has a tropical monsoon climate with temperature between $23^{\circ} \mathrm{C}$ and $32^{\circ} \mathrm{C}$ [8]. There are dry and rainy seasons without wind storms and cold winters. This area has historically been a major production area of rice, vegetable and fruit for TayNinh province and Ho Chi Minh City. However, in recent years 


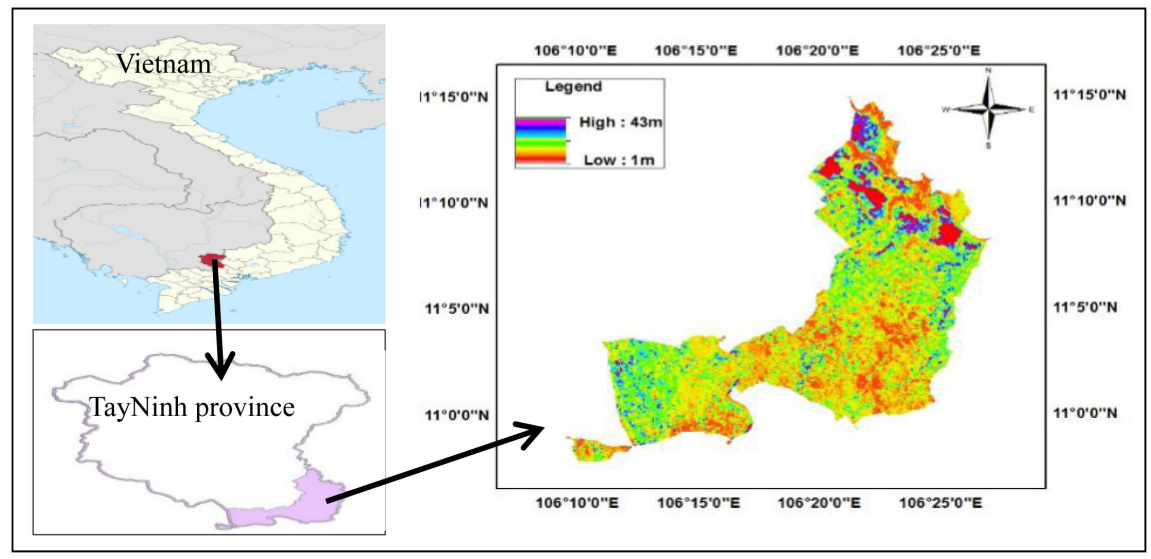

Figure 1. Location and digital elevation map of the study area.

when the economy has developed, the area of agricultural land has reduced sharply, many industrial parks have been operating there, causing the land cover to deteriorate dramatically and threaten drought and quake, severe landslide.

\subsection{Data}

Because the planning and management of land at provincial and district levels has been synchronized since 1995 in Vietnam, the data for 1995, 2007 and 2017 were used to analyze the (LULC) change over the last two decades (Table 1).

In this work, Landsat data were used to investigate the changes of LULC in Trang Bang. Three available cloud-free image scenes (Feb. 2, 1995, Feb. 3, 2007, and Feb. 28, 2017) acquired from the United States Geological Survey (USGS) Erath Resources Observation and Science Data Centre (EROS) [9]. Additionally, the corresponding land use maps $(1 / 50,000)$ for the three periods were also used to collect training samples and to evaluate classification accuracy.

The Landsat images were geometrically corrected to UTM (Universal Transverse Mercator), Zone 48 North, WGS-1984 (World Geodetic System) based on the land use maps. To do this, the control points were dispersed across each scene and the registration accuracy was less than 0.5 pixels. Supervised classification and visual interpretation methods were applied to land use/land cover types. The interpretative accuracy was $90 \%$ and kappa coefficient reached 0.85 after processing. The land use/land cover types over the study area were identified by CORINE [10] and shown in Table 2.

\subsection{Image Classification and Accuracy Evaluation}

Maximum Likelihood algorithm (ML) embedded in ENVI software was applied in this study. It is a widely used supervised image classification method. This algorithm works on the assumption that the statistics for each class in each band follow normal distribution. Then the probability of a given pixel belonging to a certain class is calculated based on the mean and standard deviation of each class obtained from the training samples. In this study, ENVI 5.0 software was used to perform the image classification. 
Table 1. Data characteristics and source.

\begin{tabular}{cccc}
\hline Data type & Year & Resolution & Source \\
\hline Landsat Image (TM) & 1995 & $30 \mathrm{~m} \times 30 \mathrm{~m}$ & NASA $^{[\mathrm{a}]}$ \\
Landsat Image (TM5) & 2007 & $30 \mathrm{~m} \times 30 \mathrm{~m}$ & USGS $^{[\mathrm{b}]}$, NASRDA $^{[\mathrm{c}]}$ \\
Landsat Image (TM8) & 2017 & $30 \mathrm{~m} \times 30 \mathrm{~m}$ & USGS \\
Maps of the actual land use & $1995,2007,2017$ & $1 / 50,000$ & Survey of study area \\
$\quad$ Population data & 1995, 2000, 2005, 2010-2017 & & TayNinh Statistical office \\
\hline [a] : National Aeronautics and Space Administration; ${ }^{[\mathrm{b}]}$ : United States Geological Survey; ${ }^{\text {[c] }: \text { National Space }}$ \\
Research and Development Agency.
\end{tabular}

Table 2. Classification of land use/land cover of the study area.

\begin{tabular}{ll}
\hline \multicolumn{1}{c}{ Level 1} & \multicolumn{1}{c}{ Level 2} \\
\hline 1) Land cover of the water & River, lake, pond, land of the Aquacultural \\
2) Land cover of the food-crops & Rice, maize, manioc, suger-cane, peanut, sweet potato \\
3) Land cover of the fruit tree & Fruit tree (durian, rambutan, jackfruit, mango), Rubber, Nacre \\
4) Land cover of the built-up & Urban, Residential, Traffic \\
5) Land cover of the industry & Industrial zone, Production business \\
6) Land cover of the shrub & Shrub, Vegetable, tobacco, grass \\
\hline
\end{tabular}

Accuracy assessment of the ML classification was determined by means of a confusion matrix (sometimes called error matrix), which compares, on a class by class basis, the relationship between reference data (ground truth) and the corresponding results of a classification [11]. Such matrices are square, with the number of rows and columns equal to the number of classes.

$$
\text { Overall accuracy }=\frac{\sum_{i=1}^{m} x_{i i}}{N} 100 \%
$$

Equation (1) is $N$ and $m$ are the total number of pixels and classes respectively. The minimum acceptable overall accuracy is $85 \%$ [12].

The Kappa coefficient $(K)$ is a second measure of classification accuracy which incorporates the off-diagonal elements as well as the diagonal terms to give a more robust assessment of accuracy than overall accuracy. It is computed as [13], [14]:

$$
K=\frac{N \sum_{i=1}^{m} x_{i i}-\sum_{i=1}^{m}\left(x_{i+} x_{+i}\right)}{N^{2}-\sum_{i=1}^{m}\left(x_{i+} x_{+i}\right)}
$$

Equation (2) is. $X_{+i}$ and $X_{i+}$. are column sum and row sum.

To calculate the Land consumption coefficient (LCC) the following formula was used:

Population projected:

$$
P(\text { projected })=P\left(t_{1}\right)+P\left(t_{2}-t_{1}\right)
$$

Equation (3) is $P$ (projected) is the projected population at present time; $P\left(t_{1}\right)$ 
is the size of the growing population at initial time; $\left(t_{1}\right)$ is Initial year; $\left(t_{2}\right)$ is Present year; $\left(t_{1}\right)$.

\section{Results and Discussion}

\subsection{Overall LULC Changes}

Land use classification results show that the area land of industrial and construction land is increasing, as shown in the land maps of 1995, 2007, 2017 (Figure 2).

The results of the land use classification are shown in Table 3, LULC has many fluctuations.

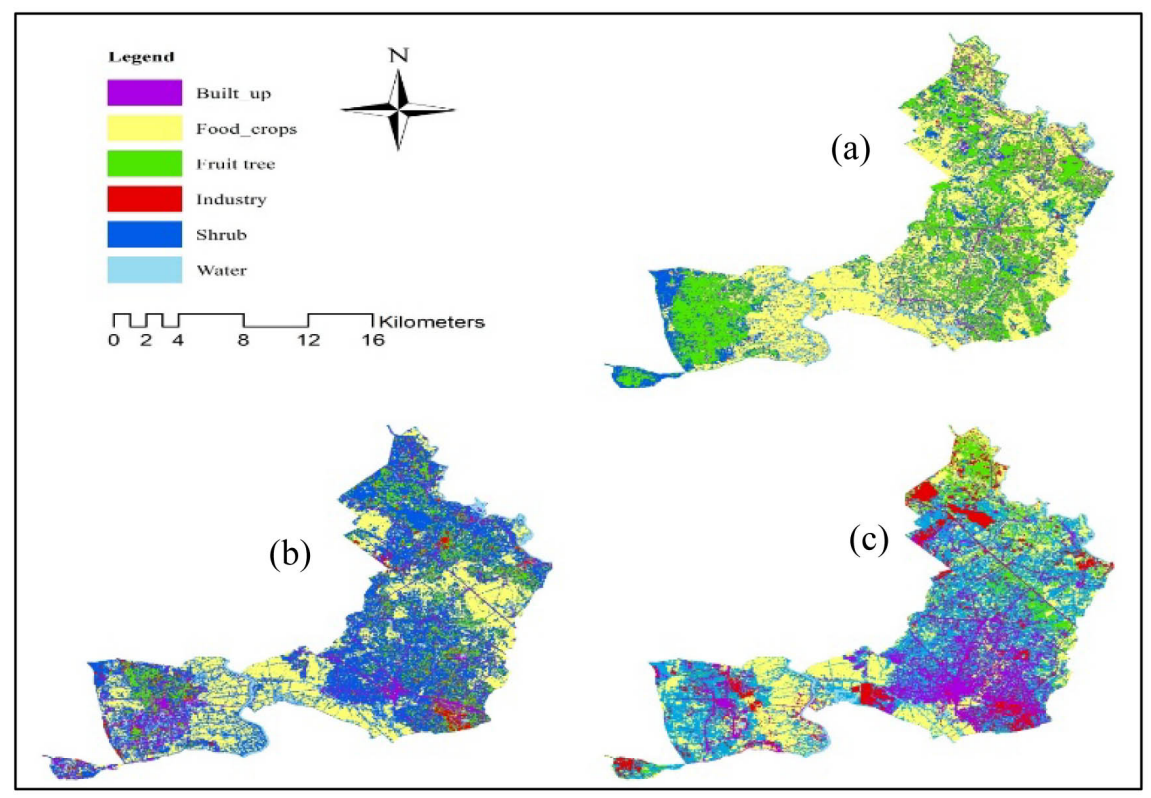

Figure 2. LULC maps (a) 1995; (b) 2007; (c) 2017.

Table 3. LULC area, change differences, classification accuracy, and Kappa statistics.

\begin{tabular}{|c|c|c|c|c|c|c|c|c|c|}
\hline \multirow{3}{*}{ LULC Classes } & \multicolumn{6}{|c|}{ Area } & \multicolumn{3}{|c|}{ Area difference $\left(\mathrm{km}^{2}\right)$} \\
\hline & \multicolumn{2}{|c|}{1995} & \multicolumn{2}{|c|}{2007} & \multicolumn{2}{|c|}{2017} & \multirow{2}{*}{$1995-2007$} & \multirow{2}{*}{$2007-2017$} & \multirow{2}{*}{$1995-2017$} \\
\hline & $\left(\mathrm{km}^{2}\right)$ & (\%) & $\left(\mathrm{km}^{2}\right)$ & (\%) & $\left(\mathrm{km}^{2}\right)$ & $(\%)$ & & & \\
\hline Food-crops & 147.6 & 43.3 & 89.3 & 26.2 & 83.3 & 24.4 & -58.3 & -6.0 & -64.3 \\
\hline Fruit-tree & 98.3 & 28.8 & 42.3 & 12.4 & 21.4 & 6.3 & -56.0 & -20.9 & -6.9 \\
\hline Water & 9.4 & 2.8 & 16.4 & 4.8 & 9.2 & 2.7 & 7.0 & -7.2 & -0.2 \\
\hline Industry & 2.1 & 0.6 & 10.8 & 3.2 & 39.4 & 11.6 & 8.7 & 28.6 & 37.3 \\
\hline Built-up & 20.4 & 6.0 & 37.2 & 10.9 & 53.1 & 15.6 & 16.8 & 15.9 & 32.7 \\
\hline Shrub & 62.9 & 18.5 & 144.7 & 42.5 & 134.3 & 39.4 & 81.8 & -10.4 & 71.4 \\
\hline TOTAL & 340.7 & 100 & 340.7 & 100 & 340.7 & 100 & & & \\
\hline Accuracy (\%) & \multicolumn{2}{|c|}{94.2} & \multicolumn{2}{|c|}{98.0} & \multicolumn{2}{|c|}{96.3} & & & \\
\hline Kappa (K) & \multicolumn{2}{|c|}{0.90} & \multicolumn{2}{|c|}{0.97} & \multicolumn{2}{|c|}{0.94} & & & \\
\hline
\end{tabular}


Analysis results show, in 1995 the area land cover of food-crops was $147.6 \mathrm{~km}^{2}$ ( $43.3 \%$ of total area), $89.3 \mathrm{~km}^{2}$ in 2007 (26.2\% of total area) and $83.3 \mathrm{~km}^{2}$ in 2017 (24. $4 \%$ of total area). In 1995 the area land cover of fruit-tree was $98.3 \mathrm{~km}^{2}$ (28.8\% of total area), $42.3 \mathrm{~km}^{2}$ in 2007 (12.4\% of total area) and $21.4 \mathrm{~km}^{2}$ in 2017 (6. $3 \%$ of total area). Built-up area in 2017 was $53.1 \mathrm{~km}^{2}$ (15.6\% of total area) (increase $15.9 \mathrm{~km}^{2}$ compared with 2007 and increase $32.7 \mathrm{~km}^{2}$ compared with 1995). Industry area in 2017 was $39.4 \mathrm{~km}^{2}$ (increase $28.6 \mathrm{~km}^{2}$ compared with 2007 and increase $37.3 \mathrm{~km}^{2}$ compared with 1995).

Shrub occupies a large area of $63.0 \mathrm{~km}^{2}$ (1995), $144.7 \mathrm{~km}^{2}$ (2007) and 134.3 $\mathrm{km}^{2}$ (2017). This type of mantle is due to the transition to mulch type land cover of food-crops. According to the statistics at the management agency, mainly from land for rice, beans to grass and tobacco. Thus this transformation of the mantle is in the second form, LULC change conversion. Because there is no forest land in the study area, the land for fruit tree is the most stable land. This land will remain $21.4 \mathrm{~km}^{2}$ by 2017 , decreased $76.9 \mathrm{~km}^{2}$ (22.6\% of the total area) in comparison with 1995.

The overall classification accuracies were $94.2 \%, 98.0 \%$, and $96.3 \%$ in 1995 , 2007, and 2017 respectively. The overall kappa coefficient of $0.90,0.97$, and 0.94 were also recorded for the image classification of 1995, 2007, and 2017 respectively. This classification results show that the land use coating in the study area is decreasing.

The chart showing the variation of the following mantle types shows the change in land cover over the years 1995, 2007 and 2017. LULC of agriculture tend to decrease, inversely proportional to the population (Figure 3 ).

The chart shows that land use over the years has been declining as built-up of land and industrial land increase. LULC in 1995 the area covered by food-crops of cover decreased $17.1 \%$ in 2007 and $18.9 \%$ in 2017. While land cover decreased relative to industrial land increased $2.6 \%$ in 2007 and $11.0 \%$ in 2017, similarly built-up of land increased 5.0\% in 2007 and $9.6 \%$ in 2017. And agricultural land tends to be inversely proportional to population growth.

\subsection{Classification Accuracy}

The reliability of the classification results is shown by the accuracy of the classification. Accuracy and Kappa $(\mathrm{K})$ coefficient show that the results of the classification are highly reliable (Table 4).

The results of the classification accuracy on each land cover are quite high, the highest is the land cover of food-crops, followed by the land cover of industry. Shrub has the lowest accuracy because this land cover has many similarities.

This classification method produces high overall accuracy were $94.2 \%, 98.0 \%$, and $96.3 \%$ in 1995, 2007, and 2017 respectively. The overall Kappa coefficient of $0.90,0.97$, and 0.94 were also recorded for the image classification of 1995, 2007, and 2017 respectively.

The accuracy between producer's and user's difference is not high in every 


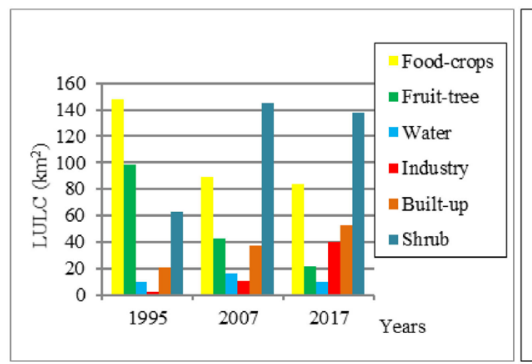

(a)

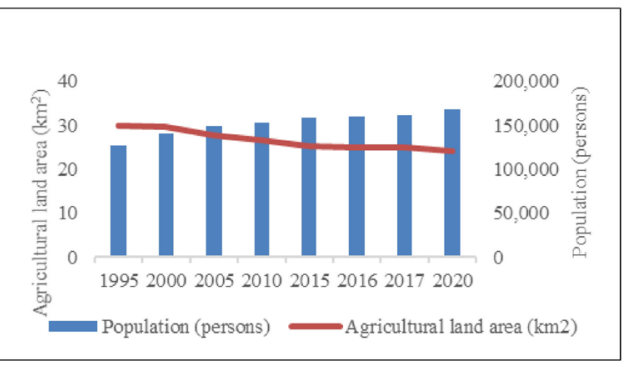

(b)

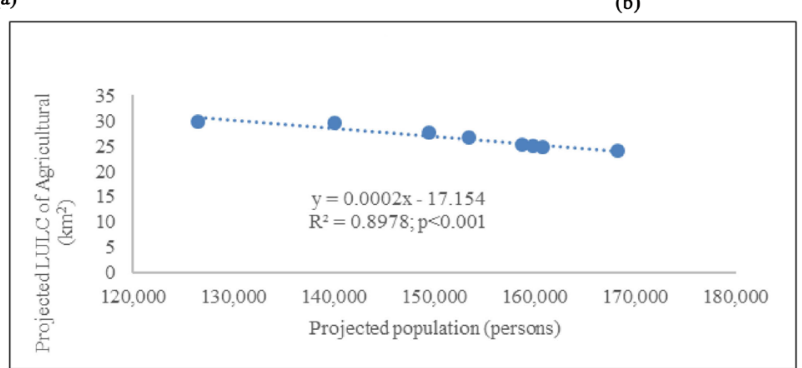

(c)

Figure 3. Summary of statistical analysis of the study area (a) comparative chart of land cover types and (b), (c) relationship between LULC of agricultural and Population.

Table 4. Producer's and user's image classification accuracies and Kappa coefficient.

\begin{tabular}{ccccccc}
\hline & \multicolumn{5}{c}{ Classification accuracies (\%) and Kappa coefficient } \\
\cline { 2 - 6 } LULC Classes & \multicolumn{2}{c}{1995} & \multicolumn{2}{c}{2007} & 2017 \\
\cline { 2 - 6 } & Producer's & User's & Producer's & User's & Producer's & User's \\
\hline Food-crops & 95.2 & 98.1 & 99.7 & 100.0 & 97.5 & 100.0 \\
Fruit-tree & 92.7 & 98.3 & 94.7 & 95.6 & 100.0 & 93.1 \\
Water & 88.8 & 93.7 & 91.9 & 100.0 & 90.9 & 100.0 \\
Industry & 100.0 & 85.7 & 98.4 & 98.0 & 95.9 & 98.8 \\
Built-up & 96.3 & 88.1 & 98.5 & 97.0 & 98.4 & 85.3 \\
Shrub & 97.8 & 79.7 & 100.0 & 93.1 & 90.6 & 70.0 \\
Accuracy (\%) & 94.2 & 93.9 & 98.0 & 97.5 & 96.3 & 96.1 \\
Kappa (K) & 0.90 & 0.87 & 0.97 & 0.95 & 0.94 & 0.92 \\
\hline
\end{tabular}

group, the highest is $100 \%$ and the lowest is $70.0 \%$. However, overall accuracy is over $85 \%$ so this result is acceptable.

\subsection{Discussion}

As a result of the analysis, the coverage area decreased sharply from 1995 to 2017 in all three types of land use: food-crops of land, fruit-tree of land and shrub of land. In particular, land for fruit-tree has the most stable coverage, because the study area has no forest so this kind of land use is considered as a perennial plant with stable coverage and plant structure less change. From 1995 to 2017 the area of fruit-tree decreased $76.9 \mathrm{~km}^{2}$, mainly to built-up of land and industry 
of land, the evidence is that other types of land cover also decrease. Map of land cover classification in 1995-2017 for matrices of changes in mulch cover over the years 1995-2017 (Table 5). This area change matrix shows that the LULC change results in Table 3 are reliable.

This study analyzes the remote sensing data in an objective and highly accurate analysis. Land use classification in 1995 was 94.2, 98.0 in 2007 and 96.3 in 2017. The Kappa coefficients in 1995, 2007 and 2017 were 0.90; 0.97 and 0.94 . Accuracy of analysis over the years is not the same because of the process of locating samples based on local statistics and land classification. And because of the structure of crops in the land of rice, vegetable and grass land is unstable. These types vary from one rice crop, two rice crop, and vegetable, which makes it difficult for statistical work. It leads to a definite sample set for the unstable classification between the two land use types: food-crops of land and shrub of land. However, according to the analysis, the accuracy of the above 90 and the Kappa coefficients above 0.9 are quite acceptable.

The above results show that the process of socio-economic development of the area along the Saigon River has a large fluctuation in LULC. For more than 2 decades (from 1995 to 2017), $141.4 \mathrm{~km}^{2}$ of land cover was lost (accounting for $41.5 \%$ ). Of which, $18.9 \%$ is reduced to food crops and $22.6 \%$ of fruit land area is reduced. Meanwhile, construction and industrial land area increased by $70 \mathrm{~km}^{2}$ (accounting for 20.5\%). In addition, the land cover in the study area is unstable (fluctuating in seasons and dependent on irrigation water, often reducing coverage in the dry season).

Because this area has no forest, this type of land use is considered to have the most stable coverage. However, the identification is also difficult due to unstable land use patterns. For example, 1-crop rice and vegetable land use only 3 to 6 months per year. The data collected is covered but the remote sensing image is vacant land. Therefore, the author classifies these into a group of shrub land, data analysis at different time is accurate.

Table 5. Cross-tabulation matrix of LULC classes between 1995-2017.

\begin{tabular}{|c|c|c|c|c|c|c|c|c|}
\hline & \multirow{2}{*}{ Class } & \multicolumn{7}{|c|}{1995} \\
\hline & & Food-crops & Fruit-tree & Water & Industry & Built-up & Shrub & Total \\
\hline \multirow{7}{*}{2017} & Food-crops & 49.7 & 11.0 & 3.1 & 14.3 & 17.7 & 52.1 & 147.9 \\
\hline & Fruit-tree & 14.7 & 5.2 & 0.8 & 15.1 & 18.3 & 44.3 & 98.4 \\
\hline & Water & 2.7 & 0.1 & 4.0 & 0.4 & 0.4 & 2.2 & 9.8 \\
\hline & Industry & 0.7 & 0.1 & 0.1 & 0.1 & 0.2 & 1.0 & 2.2 \\
\hline & Built-up & 2.6 & 1.8 & 0.0 & 3.2 & 6.2 & 7.3 & 21.1 \\
\hline & Shrub & 14.0 & 2.8 & 1.6 & 6.2 & 10.2 & 26.5 & 61.3 \\
\hline & Total & 84.4 & 21.0 & 9.6 & 39.3 & 53.0 & 133.4 & 340.7 \\
\hline
\end{tabular}




\section{Conclusions}

The rapid increase in the industrial and built-up land without checking will be a major threat to land cover, resulting in the reduction of land and habitat quality. Therefore, in order to meet the demand for economic development while ensuring the quality of land for agricultural areas, it is necessary to have a suitable economic growth policy. To focus on arranging industrial parks in agricultural production areas for poor efficiency, reduce the use of land with stable cover. In addition, it is necessary to prioritize the construction of industrial parks using materials from specific agricultural areas of the study area such as rubber, pepper, coffee, fruits, rice and vegetables. And the area of the water body should be protected and used effectively, because it is the main source of water used for irrigation for agricultural and aquaculture purposes. Industrial zones need to be managed in a way that avoids the loss of this type of land use due to pollution. Some previous domestic studies have shown that the rate of population growth and urbanization has markedly changed the LULC [15], [16]. Thus, through the results of this study, it shows that the LULC of agricultural is decreasing significantly while the population and the industrialization speed are increasing.

This area should be rather researched in order to have a more tightly managed solution which can solve both economic development and improve the quality of land and habitats on the basis of stable and sustainable development, increasing LULC.

\section{Acknowledgements}

The work described in this paper was supported by Department of Natural Resources and Environment, TayNinh province, Vietnam and Chongqing Key Laboratory of Digital Agriculture, China.

\section{Conflicts of Interest}

The authors declare no conflicts of interest regarding the publication of this paper.

\section{References}

[1] Navanugraha, C. (1996) Land Use/Land Cover Change: A Case Study in Thailand. Falculty of Environmental and Resource, Mahidol University, Thailand.

[2] Zhou, Y.S. and Skoke, D.L. (2001) Cultivated Land Use Change Analysis and Modeling: A Case Study in the Earst Region of China. Center for Global Change and Earth Observation, Michigan University.

[3] Fan, H. (2013) Land-Cover Mapping in the Nujiang Grand Canyon: Integrating Spectral, Textural, and Topographic Data in a Random Forest Classifier. International Journal of Remote Sensing, 34, 7545-7567. https://doi.org/10.1080/01431161.2013.820366

[4] Reid, R.S., Lkruska, R. and Muthui, N. (2002) Land Use and Land Cover Dynamics in Response to Changes in Climate, Biological and Socio-Political Forces, the Case of Southwestern Ethiopia. 
[5] Gautam, A.P., et al. (2002) GIS Assessment of Land Use/Land Cover Changes Associated with Community Forestry Implimentation in the Middle Hills of Nepal, Mountain Research and Development. https://doi.org/10.1659/0276-4741(2002)022[0063:GAOLUL]2.0.CO;2

[6] Dimyati, M. (2007) An Analysis of Land Use/Cover Change in Indonesia. International Journal of Remote Sensing, 931-944.

[7] TayNinh Statistical Office (2017) Statistical Yearbook 2017, 55-60.

[8] Agricultural Planning and Design Institute (1997) Socio-Economic Status, Land Use Planning of Trang Bang in TayNinh Province for the Period of 1997-2010.

[9] http://eros.usgs.gov/

[10] Heymann, Y., Steenmans, C., Croissille, G. and Bossard, M. (1994) CORINE Land Cover. Technical Guide. Office for Official Publications European Communities, Luxembourg.

[11] Story, M. and Congalton, R. (1986) Accuracy Assessment: A User's Perspective. Photogrammetric Engineering and Remote Sensing, 52, 397-399.

[12] Scepan, J. (1999) Thematic Validation of High-Resolution Global Land-Cover Data Sets. Photogrammetric Engineering and Remote Sensing, 65, 1051-1060.

[13] Jensen, J.R. (1996) Introductory Digital Image Processing: A Remote Sensing Perspective. Pearson Prentice Hall, New Jersey, USA.

[14] Viera, A.J and Garrett, J.M. (2005) Understanding Inter-Observer Agreement: The Kappa Statistic. Family 457 Medicine, 37, 360-363.

[15] Van, T.H. and Bao, H.D.X. (2014) Urban Land Cover Change through Development of Imperviousness in Ho Chi Minh City, Vietnam. https://www.researchgate.net/publication/229051773

[16] Jean-Christophe, V.N. and Verburg, P.H. (2002) Modeling of Land Cover Changes with CLUE-S in Cho Don District.

https://www.researchgate.net/publication/235951892 